\title{
Risk factors and prognosis of acute respiratory distress syndrome following abdominal surgery
}

\author{
BINGZHENG XU ${ }^{1}$, YANGLI GE ${ }^{2}$, YANGZHEN LU ${ }^{1}$, QIANQIAN CHEN ${ }^{1}$ and HONGJIN ZHANG ${ }^{1}$ \\ Departments of ${ }^{1}$ Emergency, ${ }^{2}$ Radiotherapy, Dongyang People's Hospital, Dongyang, Zhejiang 322100, P.R. China
}

Received April 16, 2018; Accepted October 16, 2018

DOI: $10.3892 /$ etm.2018.6928

\begin{abstract}
Risk factors and prognosis of acute respiratory distress syndrome (ARDS) following abdominal surgery were investigated. Five hundred and thirty-two patients who underwent abdominal surgery in Dongyang People's Hospital from February 2006 to May 2016 were enrolled. Among them, 113 patients had ARDS after surgery and 45 patients died. Those patients were included in observation group. The 419 patients who did not develop ARDS were included in control group, and 11 patients died. General data of patients were statistically analyzed, and the factors with statistical significance were subjected to multivariate logistic regression analysis to analyze the risk factors of ARDS. There was a significant difference in age, infection, trauma-to-surgery time, and prognosis between the two groups $(\mathrm{P}<0.05)$. Perioperative blood loss, blood transfusion volume, and fluid volume in the observation group were significantly higher than those in the control group $(\mathrm{P}<0.05)$. Heart rate, ratio of $\mathrm{PaO}_{2} / \mathrm{FiO}_{2}$, ratio of high (low) blood glucose, levels of procalcitonin (PCT) and albumin (ALB) were significantly different between the two groups. Heart rate, PCT, long-term health assessment (APACHE) II scores were higher in observation group than those in control group $(\mathrm{P}<0.05)$. Percentage of hyperglycemic patients, $\mathrm{PaO}_{2} / \mathrm{FiO}_{2}$, and $\mathrm{ALB}$ were lower in observation group than those in control group $(\mathrm{P}<0.05)$. Occurrence of ARDS after abdominal surgery was related to age, infection, heart rate, $\mathrm{PaO}_{2} / \mathrm{FiO}_{2}$, and PCT levels $(\mathrm{P}<0.05)$. Age, infection, heart rate, $\mathrm{PaO}_{2} / \mathrm{FiO}_{2}, \mathrm{ALB}$ and APACHE II scores were related to the prognosis of patients with ARDS after abdominal surgery $(\mathrm{P}<0.05)$. Age, infection, heart rate, $\mathrm{PaO}_{2} / \mathrm{FiO}_{2}$, PCT levels, blood loss, blood transfusion volume, and infusion volume may be risk factors for ARDS after abdominal surgery. Age, infection, heart rate, $\mathrm{PaO}_{2} / \mathrm{FiO}_{2}, \mathrm{ALB}$, and APACHE II scores may be related to prognosis of patients with ARDS after abdominal surgery.
\end{abstract}

Correspondence to: Dr Hongjin Zhang, Department of Emergency, Dongyang People's Hospital, 60 Wuning Xi Road, Wuning Town, Dongyang, Zhejiang 322100, P.R. China

E-mail: zk77ec@163.com

Key words: abdominal surgery, ARDS, risk factors, prognosis

\section{Introduction}

Acute respiratory distress syndrome (ARDS) is characterized by progressive hypoxemia caused by multiple factors. The main clinical feature of ARDS is progressive hypoxemia. Its early clinical features are increased capillary permeability and coagulation dysfunction $(1,2)$. Traumatic systemic inflammatory response caused by lung injury is considered to be the main cause of ARDS. In spite of the efforts made in the treatment of ARDS, mortality of this disease is still as high as 30-60\% (3-5). Increased incidence of abdominal trauma caused by impact injuries, crush injuries, and high-altitude crashes also increase the incidence of ARDS. Excessive infusion is also one of the main causes of ARDS. Therefore, abdominal surgery is a high risk of ARDS, and ARDS is also one of the most serious complications after abdominal injury. ARDS can cause serious disorder in the patient's internal environment, resulting in the patient's whole body sequential organ failure, which greatly increases the patient's mortality rate (6-8). However, risk factors for patients with ARDS after abdominal surgery still have not been well studied. In this study, clinical data of patients with simple abdominal trauma after surgery were retrospectively analyzed and compared between patients with and without ARDS to explore the risk factors for ARDS after abdominal surgery.

\section{Patients and methods}

Subjects. A total of 532 patients who underwent abdominal surgery from February 2006 to May 2016 in Dongyang People's Hospital (Dongyang, China) were selected. Among them, 113 patients had ARDS after surgery and 45 patients died. Those patients were included in observation group. The 419 patients who did not develop ARDS were included in control group, and 11 patients in control group died. All patients in observation group met the criteria for ARDS diagnosis (9). All patients were older than 18 years and had simple abdominal trauma. Patients with allergies, pregnant women, and patients who gave up treatment were excluded. This study was approved by the Medical Ethics Committee of Dongyang People's Hospital, and patients or their families signed informed consent.

ARDS diagnostic criteria. All 113 patients in observation group met the ARDS Berlin definition of 2012. There are 
Table I. General data.

\begin{tabular}{|c|c|c|c|c|}
\hline Characteristics & Control $(n=419)$ & Observation $(\mathrm{n}=113)$ & Statistical value & P-value \\
\hline $\operatorname{Sex}[\mathrm{n}(\%)]$ & & & 0.013 & 0.807 \\
\hline Male & $316(75.4)$ & $84(74.3)$ & & \\
\hline Female & $103(24.6)$ & $29(25.7)$ & & \\
\hline Age & $46.5 \pm 16.2$ & $55.8 \pm 16.9$ & 5.336 & $<0.001$ \\
\hline Infection $[\mathrm{n}(\%)]$ & & & 50.306 & $<0.001$ \\
\hline Yes & $71(16.9)$ & 56 (49.6) & & \\
\hline No & $348(83.1)$ & $57(50.4)$ & & \\
\hline Damage type [n (\%)] & & & 0.087 & 0.742 \\
\hline Open & $262(62.5)$ & $73(64.6)$ & & \\
\hline Closed & $157(37.5)$ & $40(35.4)$ & & \\
\hline Damaged organ number [n (\%)] & & & 0.000 & 1.000 \\
\hline$\leq 2$ & $291(69.5)$ & 79 (69.9) & & \\
\hline$>2$ & $128(30.5)$ & $34(30.1)$ & & \\
\hline Trauma-to-surgery time $[\mathrm{n}(\%)]$ & & & 23.411 & $<0.001$ \\
\hline$\leq 12 \mathrm{~h}$ & $386(92.1)$ & $85(75.2)$ & & \\
\hline$>12 \mathrm{~h}$ & $33(7.9)$ & $28(24.8)$ & & \\
\hline Prognosis [n(\%)] & & & 126.830 & $<0.001$ \\
\hline Survive & $408(97.4)$ & $68(60.2)$ & & \\
\hline Death & $11(2.6)$ & $45(39.8)$ & & \\
\hline
\end{tabular}

high risk factors for direct lung injury or indirect injury. Acute onset, heart failure, and fluid overload do not fully explain respiratory failure, and there is no high hydrostatic pulmonary edema. Hypoxemia: $\mathrm{PaO}_{2} / \mathrm{FiO}_{2} \leq 300 \mathrm{mmHg}$ in acute lung injury and $\mathrm{PaO}_{2} / \mathrm{FiO}_{2} \leq 200 \mathrm{mmHg}$ in ARDS. Chest imaging changes, chest X-ray or CT scan images show infiltrated shadows in both lungs. Pulmonary arterial wedge pressure $\leq 18 \mathrm{mmHg}$ or left atrial hypertension was excluded.

Conventional treatment. Patients in control group received conventional treatment including improvement of body's inflammatory response, fluid management, nutritional and metabolic support, respiratory support therapy, and other organ function support.

ARDS treatment plan. Patients in observation group received ARDS treatment program on the basis of routine treatment to control the causes, including drainage, debridement, antiinflammation treatment with aspirin purchased from Jiaxing Nanjian Biological Materials Co., Ltd., (item no: 50-78-2; Jiaxing, China) and hypoxemia correction. Under the premise of maintaining adequate cardiac output, early diuresis and regulation of infusion volume were performed. A lower preload of the heart was maintained so that the incarceration pressure of the pulmonary artery does not exceed $1.6 \mathrm{kPa}$. Nutrition support was performed with the total calories less than $30 \mathrm{kcal} / \mathrm{kg}$.

Observation indicators. General information including sex, age, infection, type of injury, number of damaged organs, trauma-to-operative time, prognosis and body mass index (BMI) were collected. Pretreatment heart rate, $\mathrm{PaO}_{2} / \mathrm{FiO}_{2}$, blood glucose, procalcitonin (PCT), albumin (ALB), white blood cell count (WBC), acute disease physiology, long-term health assessment (APACHE) II scores, perioperative bleeding volume, blood transfusion volume and infusion volume were also recorded.

Statistical analysis. SPSS 19.0 (SPSS, Inc., Chicago, IL, USA) was used. Enumeration data were expressed as rate, and compared by using $\chi^{2}$ test. Measurement data are expressed as mean \pm SD and distribution of data was analyzed by Kaplan-Meier method and the log-rank test. Risk factor analysis and prognostic factor analysis were performed by using logistic regression analysis. $\mathrm{P}<0.05$ was considered to indicate a statistically significant difference.

\section{Results}

General data. There were 419 patients in control group, including 316 male patients and 103 female patients, with an average age of $46.5 \pm 16.2$ years. There were 113 patients in observation group, including 84 male patients and 29 female patients, with an average age of $55.8 \pm 16.9$ years. There was no significant difference in sex proportion, injury type and number of injured organs between the two groups $(\mathrm{P}>0.05)$. There was a significant difference in age, infection, trauma-tosurgery time, and prognosis between the two groups $(\mathrm{P}<0.05)$ (Table I).

Perioperative conditions analysis. In control group, amount of blood loss was $1125.4 \pm 869.5 \mathrm{ml}$, blood transfusion volume was $756.4 \pm 642.1 \mathrm{ml}$, and infusion volume was $1725.4 \pm 744.4 \mathrm{ml}$. In observation group, blood loss volume was $2548.7 \pm 1,622.5 \mathrm{ml}$, 
Table II. Analysis of perioperative conditions (ml).

\begin{tabular}{|c|c|c|c|c|}
\hline Conditions & Control $(n=419)$ & Observation $(n=113)$ & Statistical value & P-value \\
\hline Blood loss & $1,125.4 \pm 869.5$ & $2,548.7 \pm 1,622.5$ & 12.51 & $<0.001$ \\
\hline Blood transfusion volume & $756.4 \pm 642.1$ & $1,748.6 \pm 1,215.9$ & 11.72 & $<0.001$ \\
\hline Infusion volume & $1,725.4 \pm 7,44.4$ & $3,499.4 \pm 1,819.6$ & 15.70 & $<0.001$ \\
\hline
\end{tabular}

Table III. Analysis of vital signs of two groups of patients.

\begin{tabular}{|c|c|c|c|c|}
\hline Vital signs & Control $(n=419)$ & Observation $(\mathrm{n}=113)$ & Statistical value & P-value \\
\hline BMI [n (\%)] & & & 0.375 & 0.521 \\
\hline$<25 \mathrm{~kg} / \mathrm{m}^{2}$ & $177(42.2)$ & $52(46.0)$ & & \\
\hline$\geq 25 \mathrm{~kg} / \mathrm{m}^{2}$ & $242(57.8)$ & $61(54.0)$ & & \\
\hline Heart rate (times/min) & $95.47 \pm 10.42$ & $98.41 \pm 11.32$ & 2.612 & 0.009 \\
\hline $\mathrm{PaO}_{2} / \mathrm{FiO}_{2}(\mathrm{mmHg})$ & $136.75 \pm 56.45$ & $121.44 \pm 49.26$ & 2.626 & 0.009 \\
\hline Blood glucose [n (\%)] & & & 14.475 & $<0.001$ \\
\hline$\leq 150 \mathrm{mg} / \mathrm{dl}$ & $316(75.4)$ & $64(56.6)$ & & \\
\hline$>150 \mathrm{mg} / \mathrm{dl}$ & $103(24.6)$ & $49(43.4)$ & & \\
\hline $\operatorname{PCT}(\mu \mathrm{g} / \mathrm{l})$ & $4.2 \pm 1.7$ & $4.6 \pm 1.5$ & 2.274 & 0.023 \\
\hline $\operatorname{ALB}(g / l)$ & $27.2 \pm 3.8$ & $25.4 \pm 5.7$ & 3.974 & $<0.001$ \\
\hline WBC (x109/1) & $11.9 \pm 6.8$ & $12.2 \pm 7.1$ & 0.412 & 0.680 \\
\hline
\end{tabular}

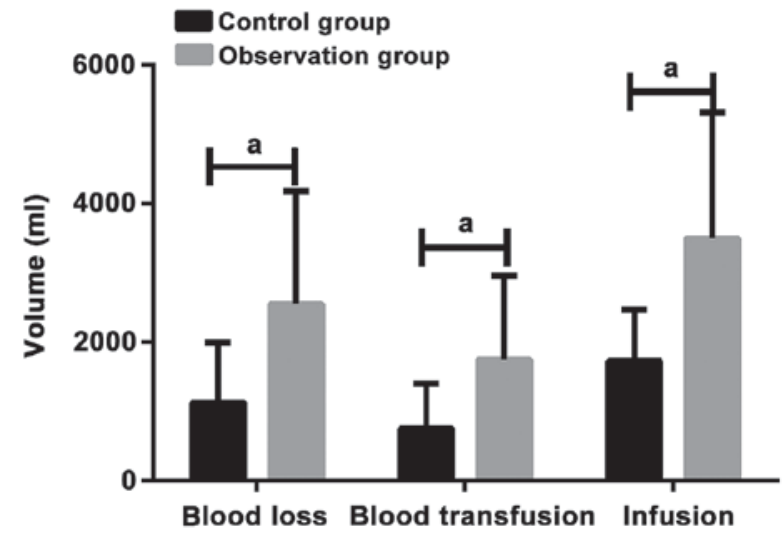

Figure 1. Analysis of perioperative conditions. The perioperative blood loss, blood transfusion and fluid transfusion volume in the observation group were significantly higher than those in the control group. ${ }^{\text {aP }}<0.05$.

blood transfusion volume was $1748.6 \pm 1,215.9 \mathrm{ml}$, and infusion volume was $3499.4 \pm 1819.6 \mathrm{ml}$. The perioperative blood loss, blood transfusion, and infusion volume in observation group were significantly higher than those in control group $(\mathrm{P}<0.05)$ (Table II and Fig. 1).

Analysis of vital signs of two groups of patients. There was no significant difference in BMI and WBC between two groups $(\mathrm{P}>0.05)$. There were differences in heart rate, $\mathrm{PaO}_{2} / \mathrm{FiO}_{2}$, ratio of high (low) glucose, PCT, and ALB between two groups. Heart rate and PCT were higher in observation group than in control group $(\mathrm{P}<0.05)$. Percentage of hyperglycemic

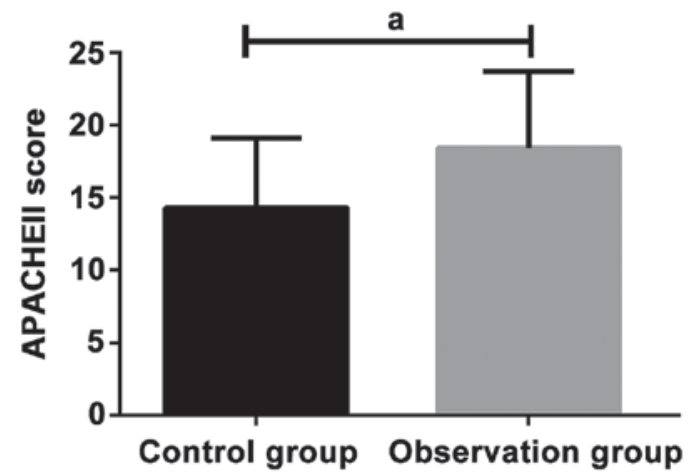

Figure 2. APACHE II score results. The APACHE II score in the observation group was higher than that in the control group. ${ }^{\mathrm{a}} \mathrm{P}<0.05$.

patients, $\mathrm{PaO}_{2} / \mathrm{FiO}_{2}$, and $\mathrm{ALB}$ were lower in observation group than those in control group $(\mathrm{P}<0.05$, Table III).

Comparison of APACHE II score between two groups. APACHE II score in control group was $14.3 \pm 4.8$, and APACHE II score in observation group was $18.4 \pm 5.3$. There was a significant difference in APACHE II score between two groups. APACHE II score in observation group was higher than that in the control group $(\mathrm{P}<0.05)$ (Fig. 2).

Analysis of risk factors for ARDS after abdominal surgery. Occurrence of ARDS (yes=1, no=0) was set as a dependent variable, and factors with statistical significance were set as independent variables for logistic regression analysis. Results 
Table IV. Analysis of risk factors for ARDS after abdominal surgery.

\begin{tabular}{lrcc}
\hline Factors & \multicolumn{1}{c}{ OR } & $95 \% \mathrm{CI}$ & P-value \\
\hline Age & 1.463 & $1.064-2.013$ & 0.031 \\
Infection & 1.389 & $1.042-1.852$ & 0.036 \\
Trauma-to-surgery time & 0.871 & $0.672-1.130$ & 0.152 \\
$\mathrm{Heart} \mathrm{rate}_{\mathrm{PaO}_{2} / \mathrm{FiO}_{2}}$ & 0.457 & $0.261-0.801$ & 0.019 \\
$\mathrm{Blood} \mathrm{glucose}_{\mathrm{PCT}}$ & 0.192 & $0.056-0.661$ & 0.024 \\
$\mathrm{ALB}$ & 1.814 & $0.925-3.558$ & 0.072 \\
Blood loss & 0.674 & $0.486-0.930$ & 0.029 \\
Blood transfusion & 1.143 & $0.978-1.335$ & 0.047 \\
Infusion volume & 0.457 & $0.261-0.801$ & 0.025 \\
& 13.228 & $1.883-92.936$ & 0.001 \\
& 1.483 & $1.096-1.975$ & 0.016 \\
\hline
\end{tabular}

Table V. Prognostic analysis results.

\begin{tabular}{lccc}
\hline Factors & OR & $95 \% \mathrm{CI}$ & P-value \\
\hline Age & 1.210 & $1.020-1.436$ & 0.040 \\
Infection & 0.702 & $0.499-0.986$ & 0.048 \\
Heart rate & 1.281 & $1.031-1.591$ & 0.036 \\
$\mathrm{PaO}_{2} / \mathrm{FiO}_{2}$ & 0.529 & $0.306-0.916$ & 0.035 \\
$\mathrm{PCT}$ & 0.789 & $0.625-0.996$ & 0.053 \\
$\mathrm{ALB}$ & 1.385 & $0.987-1.683$ & 0.023 \\
APACHE II score & 2.380 & $1.341-4.222$ & 0.011 \\
\hline
\end{tabular}

showed that occurrence of ARDS after abdominal surgery was significantly correlated with age, infection, heart rate, $\mathrm{PaO}_{2} / \mathrm{FiO}_{2}$, PCT levels, blood loss, blood transfusion volume, and fluid volume $(\mathrm{P}<0.05)$, but was not correlated with blood glucose and trauma-to-surgery time $(\mathrm{P}>0.05)$ (Table IV).

Prognostic analysis results. Death of ARDS patients after abdominal surgery was set as a dependent variable (yes $=1$, no=0), and factors associated with ARDS after abdominal surgery and APACHE II score were used as independent variables to carry out logistic regression analysis. Results showed that age, infection, heart rate, $\mathrm{PaO}_{2} / \mathrm{FiO}_{2}, \mathrm{ALB}$, and APACHE II scores were related to the prognosis of ARDS patients after abdominal surgery $(\mathrm{P}<0.05)$, while PCT levels were not related to their prognosis $(\mathrm{P}>0.05$, Table $\mathrm{V})$.

\section{Discussion}

Pathogenesis of ARDS mainly includes direct and indirect lung injury. Trauma is one of the main causes of indirect lung injury-induced ARDS, and surgery is also a type of trauma. It has been reported that approximately $25 \%$ of multiple trauma patients and approximately $40 \%$ of emergency infusion patients are complicated by ARDS. Although in recent years, due to the application of mechanical ventilation in clinical treatment and the improved cognition on ARDS, mortality rate of patients with ARDS has declined, but is still high (10-12). Therefore, our study aimed to identify risk factors and prognostic factors of patients with postoperative ARDS, and provide references for clinical treatment and prognosis of patients with ARDS.

In this study, clinical data of 532 patients undergoing surgical treatment in Dongyang People's Hospital due to simple abdominal trauma were retrospectively analyzed. Among them, ARDS occurred in 113 patients and incidence was approximately $21.2 \%$, which is consistent with previous studies $(13,14)$. Significant differences in age, infection, heart rate, $\mathrm{PaO}_{2} / \mathrm{FiO}_{2}$, PCT levels, ALB levels, APACHE II scores, trauma-to-surgery time, blood glucose, blood loss, blood transfusion volume, and infusion volume were found between two groups. We first analyzed risk factors for ARDS after abdominal surgery. Logistic regression analysis showed age, infection, heart rate, $\mathrm{PaO}_{2} / \mathrm{FiO}_{2}$, PCT levels, blood loss, blood transfusion, and infusion volume were closely correlated with the occurrence of ARDS. Older patients have poor organ storage function compared to younger patients, and have less resistance to post-traumatic infections and stress responses, and are more prone to organ damage (15). Results of this study also showed that patients with ARDS after surgery are older and had higher infection rates than patients without ARDS. PCT test results also showed that patients with ARDS had higher PCT levels than patients without ARDS. ALB is an acute phase protein. It has been reported that hypoproteinemia is an independent risk factor for severe ARDS patients complicated with ARDS, leading to a significant increase in mortality $(16,17)$.

Hypoproteinemia also affects the patient's colloidal osmotic pressure, promotes pulmonary edema, and affects patient's oxygenation capacity (18). Results of this study also showed that ALB levels and $\mathrm{PaO}_{2} / \mathrm{FiO}_{2}$ in patients with postoperative ARDS were significantly lower than those in patients without ARDS. Amount of blood loss, blood transfusion, and infusion volume in ARDS patients were significantly higher than those in patients without ARDS. Excessive infusion during surgical operation can dilute blood and decrease plasma colloid osmotic pressure, further promoting the aggregation of pulmonary edema and reducing oxygenation ability. Some denatured proteins may also present in blood with longer storage time and affect patients' coagulation function $(19,20)$. Therefore, effectively shortening operation time, effectively and quickly treating the wound, and timely regulating liquid input during operation may be an effective means for preventing postoperative ARDS.

We then analyzed the prognostic factors of ARDS. In this study, among 113 patients, 45 patients died of ARDS after surgery, and the mortality rate was $39.8 \%$, which is consistent with the findings in previous studies $(21,22)$. Prognostic factors of ARDS have long been a focus of clinical concern. Some studies have reported that mortality of patients with ARDS is closely related to age, oxygenation index, MODS score, and APACHE II score $(23,24)$. Consistently, we also found that the patient's age, oxygenation index, MODS score, and APACHE II are closely related to prognosis. APACHE II score is more comprehensive than MODS score. Studies have reported that many patients with ARDS have organ damage, and APACHE II score is also more sensitive to the prognosis of patients with ARDS $(25,26)$. Therefore, MODS was not used in this study. Sensitivity of elderly patients to drug treatment is poor, which 
may be a cause of poor prognosis in elderly patients. Moreover, immune function of elderly patients is relatively poor, and immunosuppressants can be used during treatment to support systemic treatment. Tracheal intubation and mechanical ventilation may also be performed to avoid the occurrence of multiple infections. This study also has limitations. Due to the limited experimental resources, some indicators, such as status of infected bacteria, have not been included in the study. We will include those factors in our future studies.

In summary, age, infection, heart rate, $\mathrm{PaO}_{2} / \mathrm{FiO}_{2}$, PCT levels, blood loss, blood transfusion, and infusion volume may be risk factors for ARDS after abdominal surgery. Age, infection, heart rate, $\mathrm{PaO}_{2} / \mathrm{FiO}_{2}, \mathrm{ALB}$ and APACHE II scores may be related to the prognosis of patients with ARDS after abdominal surgery.

\section{Acknowledgements}

Not applicable.

\section{Funding}

No funding was received.

\section{Availability of data and materials}

The datasets used and/or analyzed during the present study are available from the corresponding author on reasonable request.

\section{Authors' contributions}

$\mathrm{BX}$ wrote the manuscript. BX and YG treated patients and collected the basic data of patients. YL worked on ARDS treatment program for patients. QC and $\mathrm{HZ}$ were responsible for prognostic analysis. All authors read and approved the final manuscript.

\section{Ethics approval and consent to participate}

The study was approved by the Ethics Committee of Dongyang People's Hospital (Dongyang, China). Signed informed consents were obtained from the patients or the guardians.

\section{Patient consent for publication}

Not applicable.

\section{Competing interests}

The authors declare that they have no competing interests.

\section{References}

1. Thompson BT, Chambers RC and Liu KD: Acute respiratory distress syndrome. N Engl J Med 377: 562-572, 2017.

2. Sweeney RM and McAuley DF: Acute respiratory distress syndrome. Lancet 388: 2416-2430, 2016.

3. Stevens JP, Law A and Giannakoulis J: Acute respiratory distress syndrome. JAMA 319: 732, 2018.

4. Chang Y, Park SH, Huh J-W, Lim C-M, Koh Y and Hong S-B: Intratracheal administration of umbilical cord blood-derived mesenchymal stem cells in a patient with acute respiratory distress syndrome. J Korean Med Sci 29: 438-440, 2014.
5. Grissom CK, Hirshberg EL, Dickerson JB, Brown SM, Lanspa MJ, Liu KD, Schoenfeld D, Tidswell M, Hite RD, Rock P, et al; National Heart Lung and Blood Institute Acute Respiratory Distress Syndrome Clinical Trials Network: Fluid management with a simplified conservative protocol for the acute respiratory distress syndrome. Crit Care Med 43: 288-295, 2015.

6. Bellani G, Laffey JG, Pham T, Fan E, Brochard L, Esteban A Gattinoni L, van Haren F, Larsson A, McAuley DF, et al; LUNG SAFE Investigators; ESICM Trials Group: Epidemiology, patterns of care, and mortality for patients with acute respiratory distress syndrome in intensive care units in 50 countries. JAMA 315: 788-800, 2016.

7. Amato MB, Meade MO, Slutsky AS, Brochard L, Costa EL, Schoenfeld DA, Stewart TE, Briel M, Talmor D, Mercat A, et al: Driving pressure and survival in the acute respiratory distress syndrome. N Engl J Med 372: 747-755, 2015.

8. Pediatric Acute Lung Injury Consensus Conference Group: Pediatric acute respiratory distress syndrome: Consensus recommendations from the Pediatric Acute Lung Injury Consensus Conference. Pediatr Crit Care Med 16: 428-439, 2015.

9. Dizier S, Forel JM, Ayzac L, Richard JC, Hraiech S, Lehingue S, Loundou A, Roch A, Guerin C and Papazian L; ACURASYS study investigators; PROSEVA Study Group: Early hepatic dysfunction is associated with a worse outcome in patients presenting with acute respiratory distress syndrome: A post-hoc analysis of the ACURASYS and PROSEVA Studies. PLoS One 10: e0144278, 2015.

10. Patel BK, Wolfe KS, Pohlman AS, Hall JB and Kress JP: Effect of noninvasive ventilation delivered by helmet vs face mask on the rate of endotracheal intubation in patients with acute respiratory distress syndrome: A randomized clinical trial. JAMA 315: 2435-2441, 2016.

11. Needham DM, Yang T, Dinglas VD, Mendez-Tellez PA, Shanholtz C, Sevransky JE, Brower RG, Pronovost PJ and Colantuoni E: Timing of low tidal volume ventilation and intensive care unit mortality in acute respiratory distress syndrome. A prospective cohort study. Am J Respir Crit Care Med 191: 177-185, 2015.

12. Villar J, Blanco J and Kacmarek RM: Current incidence and outcome of the acute respiratory distress syndrome. Curr Opin Crit Care 22: 1-6, 2016.

13. Neto AS, Simonis FD, Barbas CS, Biehl M, Determann RM, Elmer J, Friedman G, Gajic O, Goldstein JN, Linko R, et al; PROtective Ventilation Network Investigators: Lung-protective ventilation with low tidal volumes and the occurrence of pulmonary complications in patients without acute respiratory distress syndrome: A systematic review and individual patient data analysis. Crit Care Med 43: 2155-2163, 2015.

14. Mekontso Dessap A, Boissier F, Charron C, Bégot E, Repessé X, Legras A, Brun-Buisson C, Vignon P and Vieillard-Baron A: Acute cor pulmonale during protective ventilation for acute respiratory distress syndrome: Prevalence, predictors, and clinical impact. Intensive Care Med 42: 862-870, 2016.

15. Cressoni M, Cadringher P, Chiurazzi C, Amini M, Gallazzi E, Marino A, Brioni M, Carlesso E, Chiumello D, Quintel M, et al: Lung inhomogeneity in patients with acute respiratory distress syndrome. Am J Respir Crit Care Med 189: 149-158, 2014.

16. Caironi P, Tognoni G, Masson S, Fumagalli R, Pesenti A, Romero M, Fanizza C, Caspani L, Faenza S, Grasselli G, et al; ALBIOS Study Investigators: Albumin replacement in patients with severe sepsis or septic shock. N Engl J Med 370: 1412-1421, 2014.

17. Masson S, Caironi P, Fanizza C, Carrer S, Caricato A, Fassini P, Vago T, Romero M, Tognoni G, Gattinoni L, et al; Albumin Italian Outcome Sepsis Study Investigators: Sequential $\mathrm{N}$-terminal pro-B-type natriuretic peptide and high-sensitivity cardiac troponin measurements during albumin replacement in patients with severe sepsis or septic shock. Crit Care Med 44: 707-716, 2016.

18. Tokgöz Y, Erdur B and Öztürk Y: HLA subtypes and Helicobacter pylori infection in an infant with celiac crisis. Turk J Gastroenterol 24: 74-76, 2013.

19. Horowitz M, Neeman E, Sharon E and Ben-Eliyahu S: Exploiting the critical perioperative period to improve long-term cancer outcomes. Nat Rev Clin Oncol 12: 213-226, 2015.

20. Ecker BL, Simmons KD, Zaheer S, Poe SL, Bartlett EK, Drebin JA, Fraker DL, Kelz RR, Roses RE and Karakousis GC: Blood transfusion in major abdominal surgery for malignant tumors: A trend analysis using the National Surgical Quality Improvement Program. JAMA Surg 151: 518-525, 2016. 
21. Calfee CS, Delucchi K, Parsons PE, Thompson BT, Ware LB and Matthay MA; NHLBI ARDS Network: Subphenotypes in acute respiratory distress syndrome: Latent class analysis of data from two randomised controlled trials. Lancet Respir Med 2: 611-620, 2014.

22. Schmidt M, Stewart C, Bailey M, Nieszkowska A, Kelly J, Murphy L, Pilcher D, Cooper DJ, Scheinkestel C, Pellegrino $\mathrm{V}$, et al: Mechanical ventilation management during extracorporeal membrane oxygenation for acute respiratory distress syndrome: A retrospective international multicenter study. Crit Care Med 43: 654-664, 2015.

23. Wang Z, Wei Y, Tejera P, Su L, Bajwa EK and Christiani DC: A functional missense SNP in LRRC16A contributes to an improved prognosis of ARDS patients mediated through attenuated platelet count decline in ICU. Am J Respir Crit Care Med 193: A7489, 2016.

24. Hendrickson CM and Matthay MA: Endothelial biomarkers in human sepsis: Pathogenesis and prognosis for ARDS. Pulm Circ 8: 2045894018769876, 2018.
25. Qi SY, Wang WT, Chu ZD, Chen CY, Zhou MK, Ren YX and Liu XJ: The clinical analysis of extracorporeal membrane oxygenation for adult severe acute respiratory distress syndrome. Zhonghua Jie He He Hu Xi Za Zhi 39: 291-297, 2016 (In Chinese). 26. Zhu Q, Pan X, Cao Y, Wang H, Yu N, Liu F, Yang S, Wang Y, Sun Y and Wang Z: Clinical evaluation of continuous renal replacement therapy in combination with ultrasound-guided percutaneous transhepatic gallbladder drainage for acute severe biliary pancreatitis: A retrospective study. Kidney Blood Press Res 42: 1023-1032, 2017.

This work is licensed under a Creative Commons Attribution-NonCommercial-NoDerivatives 4.0 International (CC BY-NC-ND 4.0) License. 